\title{
Experimental Study of the Ductility of a Submerged Arc Welded Corner Joint in a High-Performance Steel Built-Up Box Column
}

\author{
Satoshi Yamada ${ }^{1} \cdot$ Yuko Shimada $^{2}\left({ }^{10} \cdot\right.$ Takanori Ishida $^{1} \cdot$ Yuka Matsumoto $^{3} \cdot$ Jun Iyama $^{4} \cdot$ Hiroumi Shimokawa $^{5}$. \\ Hiroshi Ito $^{6}$ - Satoshi Aoyagi ${ }^{6}$
}

Received: 21 March 2019 / Accepted: 16 July 2020 / Published online: 7 August 2020

(c) The Author(s) 2020

\begin{abstract}
Submerged arc welding, which is generally used for the corner joint of box-section columns, is a welding process with a high heat input. The influence on the strength and toughness of the heat-affected zone is an important concern, especially when used with a high-performance steel that may be more susceptible to heat input. The ductility of the welded corner joint is one of the important factors to ensure safety against external forces, such as during severe earthquakes. In this study, a series of material and cyclic loading tests of the corner joint comprising SA440C high-performance steel fabricated by submerged arc welding were conducted. The experimental results indicated that the welded corner joint comprising SA440C steel is ductile enough to dissipate input energy caused by the strong ground motion from an earthquake.
\end{abstract}

Keywords Submerged arc welding $\cdot$ High-performance steel $\cdot$ Cyclic loading test $\cdot$ Ductility

\section{Introduction}

In Japan, square hollow section (SHS) members are used as columns in steel moment-resisting frames in most building structures because the SHS behaves similarly against the bending moment around any axis and it is easy to design a bidirectional moment frame with high seismic resistance. For low- and middle-rise buildings, cold-formed SHS steel tubes are used in many cases. However, for high-rise buildings, built-up box sections fabricated using thick plates of high-strength or high-performance steel are often used because such large SHS steel tubes produced by cold-form

Yuko Shimada

yshimada@faculty.chiba-u.jp

1 Institute of Innovative Research, Tokyo Institute of Technology, Yokohama 226-8503, Japan

2 Graduate School and Faculty of Engineering, Chiba University, Chiba 263-8522, Japan

3 Institute of Urban Innovation, Yokohama National University, Yokohama 240-8501, Japan

4 School of Engineering, The University of Tokyo, Tokyo 113-8656, Japan

5 JFE Steel Corporation, Tokyo 100-0011, Japan

6 Nippon Steel Corporation, Tokyo 100-8071, Japan processes are not available. Currently, the strongest steel generally used for built-up box columns in Japan is SA440C with a tensile strength of $590 \mathrm{~N} / \mathrm{mm}^{2}$ (The Japan Iron and Steel Federation (JISF) 2004). Thus, as SA440C is a heattreated steel, heat input by welding may substantially affect the mechanical properties, i.e., the strength and toughness of the heat affected zone (HAZ).

Built-up box members are fabricated by assembling four steel plates and welding by submerged arc welding (SAW), as shown in Fig. 1. Because SAW has a high heat input, the influence on strength and toughness at the HAZ is of concern. Based on many studies of SAW of high-strength steel (Yoshida et al. 1963; Wada et al. 1998; Kojima et al. 2004), welding conditions that ensure the strength and toughness of welded parts have been specified and are used in Japan (JISF 2016).

Previous studies focused on the tensile strength of the butt welding or the HAZ toughness of the corner joint by SAW. However, the stress and strain conditions around the corner joint of the box-column are completely different. Figure $2 \mathrm{~b}$ schematically shows the deformation of the box column around the beam-to-column joint. This is the possible worst case where there is no diaphragm (or continuity plate) and the column face plate is subjected to a tensile force in the out-of-plane direction as shown in Fig. 2a. The corner of the column may be subjected to an opening and closing 


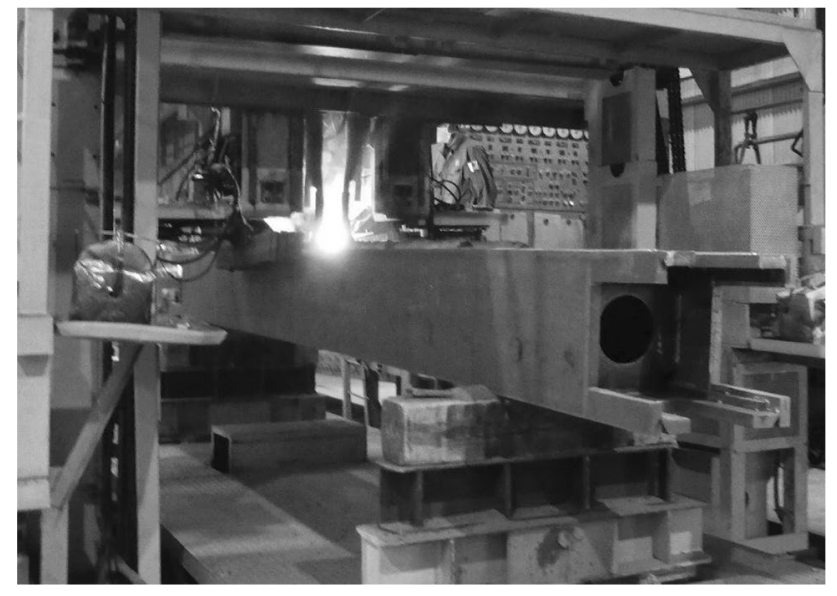

Fig. 1 Fabrication of the built-up box column by SAW force, as shown in Fig. 2c. However, it has not been verified whether, or not, a corner joint in columns has enough ductility to withstand such force. In this study, to investigate the ductility of a welded corner joint comprising SA440C steel box-columns fabricated by SAW, a series of material tests and cyclic loading tests were conducted (Table 1).

\section{Fabrication of Built-Up Box Column}

First, a built-up box column was fabricated, and test specimens were extracted from it later. The shape of the column and welding detail are shown in Fig. 3. This is the same column used in the electro-slag welding (ESW) test for SA440C steel (Iyama et al. 2019). It has a section with dimensions of $800 \mathrm{~mm} \times 800 \mathrm{~mm} \times 36 \mathrm{~mm}$ and is fabricated with SA440C

Fig. 2 Deformation of the box-column around the beamto-column joint. a Assumed failure situation, $\mathbf{b}$ Close-up of joint deformation, $\mathbf{c}$ Bending of submerged arc weld

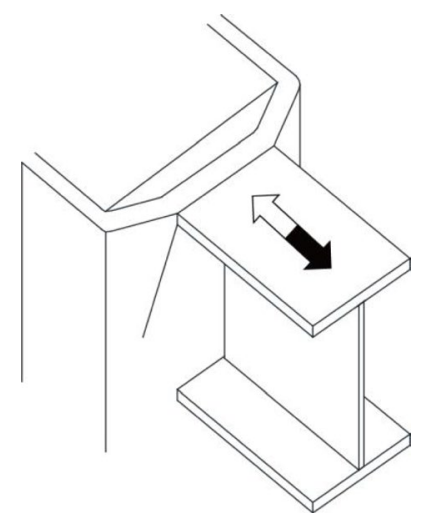

(a)

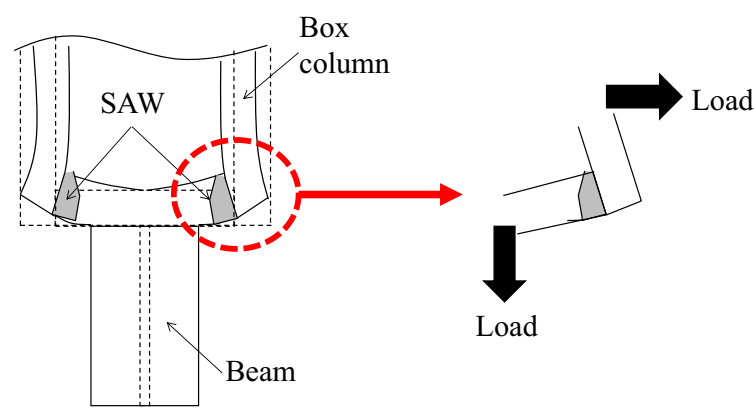

(b) (c)
Table 1 Material property of SA440C

\begin{tabular}{|c|c|c|c|c|c|c|}
\hline \multirow[t]{2}{*}{ Material } & \multicolumn{2}{|c|}{ Yield point $\left(\mathrm{N} / \mathrm{mm}^{2}\right)$} & \multicolumn{2}{|c|}{$\begin{array}{l}\text { Tensile strength (N/ } \\
\left.\mathrm{mm}^{2}\right)\end{array}$} & \multirow[t]{2}{*}{ Fracture elongation (\%) } & \multirow[t]{2}{*}{ Yield ratio $(\%)$} \\
\hline & Lower & Upper & Lower & Upper & & \\
\hline SA440C & 440 & 540 & 590 & 740 & $>26$ & $\leq 80$ \\
\hline
\end{tabular}

(Based on JISF 2004)
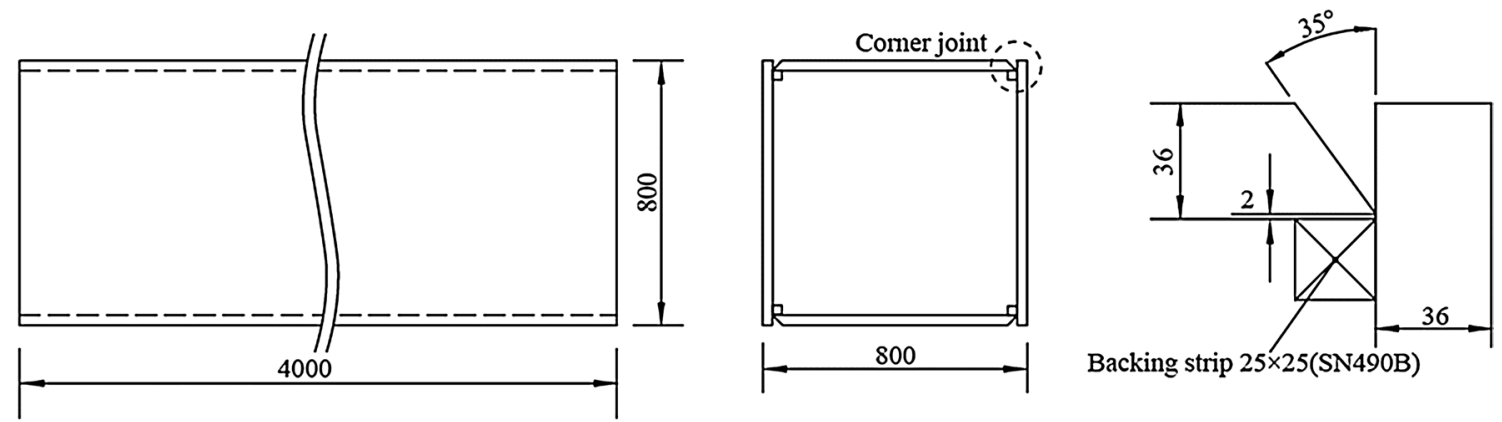

Fig. 3 Built-up box column 
Table 2 SAW conditions

\begin{tabular}{lllllll}
\hline Wire & Flux & Electrode & Current $(\mathrm{A})$ & Voltage $(\mathrm{V})$ & Speed $(\mathrm{cm} / \mathrm{min})$ & Heat input $(\mathrm{kJ} / \mathrm{cm})$ \\
\hline YS-NM1, ф6.4 & \multirow{2}{*}{ SACI1 } & $\mathrm{L}$ & 1700 & 35 & 26 & 296.5 \\
& & $\mathrm{~T}$ & 1500 & 46 & & \\
\hline
\end{tabular}

"L" is the leading electrode and "T" is the trailing electrode

Table 3 Chemical composition of steel

\begin{tabular}{lllllllllllll}
\hline Location & $\mathrm{C}(\%)$ & $\mathrm{Si}(\%)$ & $\mathrm{Mn}(\%)$ & $\mathrm{P}(\%)$ & $\mathrm{S}(\%)$ & $\mathrm{Cu}(\%)$ & $\mathrm{Ni}(\%)$ & $\mathrm{Cr}(\%)$ & $\mathrm{Mo}(\%)$ & $\mathrm{V}(\%)$ & $\mathrm{B}(\%)$ & $\mathrm{N}(\%)$ \\
\hline Base metal & 0.10 & 0.26 & 1.44 & 0.008 & 0.001 & 0.23 & 0.18 & 0.01 & 0.16 & 0.046 & 0.0001 & 0.0039 \\
Weld metal & 0.08 & 0.38 & 1.18 & 0.01 & 0.004 & 0.16 & 0.39 & 0.03 & 0.44 & 0.029 & 0.0031 & 0.0044 \\
Backing strip & 0.13 & 0.23 & 1.31 & 0.018 & 0.006 & 0.10 & 0.05 & 0.11 & 0.01 & 0.039 & 0.0003 & 0.0096 \\
\hline
\end{tabular}

Table 4 Chemical composition of flux

\begin{tabular}{lll}
\hline $\mathrm{CaO}+\mathrm{Mgo}(\%)$ & $\mathrm{Fe}(\%)$ & $\mathrm{CO}_{2}(\%)$ \\
\hline 64.0 & 26.6 & 3.2 \\
\hline
\end{tabular}

steel for the flange plate and SN490B steel for the backing strip. The column flange plates were welded to each other by double-electrode SAW with a single welding pass. There is a single bevel groove with an angle of $35^{\circ}$ and a root gap of $0 \mathrm{~mm}$. The welding conditions and materials are shown in Table 2. This is the current standard welding condition for high-performance steel SA440C in Japan according to JISF (2016).

The welding wire is according to JIS (Japanese Industrial Standards) Z3351, and welding flux is according to JIS Z3352. The chemical composition of the base metal (column flange plate), backing strip and weld metal obtained by spectroscopic analysis of samples cut from the box column are shown in Table 3. The chemical composition of the flux is shown in Table 4.

\section{Mechanical Properties}

\subsection{Coupon Test}

\subsubsection{Specimen for the Coupon Test}

The A2-type specimen defined in JIS Z3111 was used for the tensile coupon test, which is shown in Fig. 4. Specimens were cut from the base metal (BM), weld metal (WM), and heat affected zone (HAZ). The BM specimen was cut from SA440C steel, which was the surplus of the built-up box column. The locations where specimens of WM and HAZ were cut from are shown in Fig. 5. WM specimens were cut from the center of the weld metal at $16 \mathrm{~mm}$ from the surface.

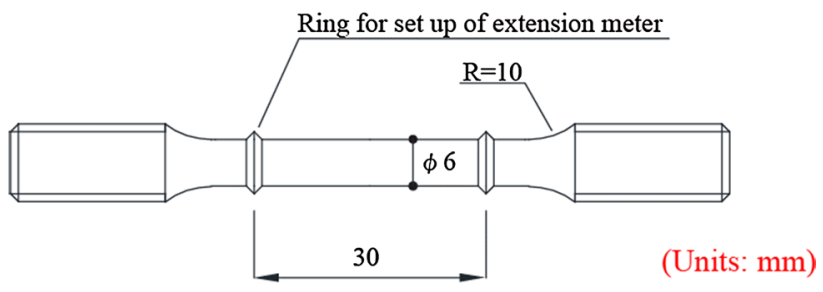

Fig. 4 Shape of the A2-type specimen (JIS Z3111)

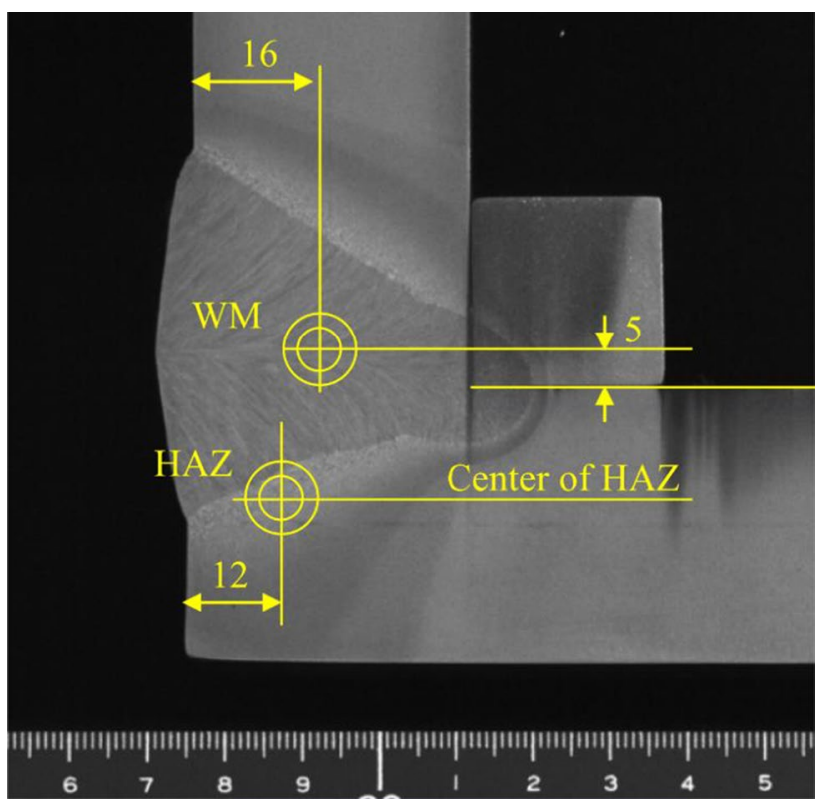

Fig. 5 Locations of specimens used for the coupon tests

HAZ specimens were cut from the center of the heat affected zone at $12 \mathrm{~mm}$ from the surface. The location of the center of HAZ specimens from the fusion line were determined by the macroscopic test. 


\subsubsection{Testing Condition of the Coupon Test}

The tensile test was conducted in a temperature-controlled chamber at $0{ }^{\circ} \mathrm{C}$ in order to confirm the yield point and tensile strength under same temperature as the bending test of corner welding. The temperature of the test specimens was continuously monitored by two thermocouples, and the tensile test was initiated after confirming that the temperature reached $0{ }^{\circ} \mathrm{C}$.

\subsubsection{Results of the Coupon Test}

The stress-strain relationships of the BM, WM, and HAZ are shown in Fig. 6. The obtained test results are summarized in Table 5. For the HAZ specimen, because yield points did not clearly appear in the stress-strain relationships, the $0.2 \%$ offset strength was taken as yield point in the table. For the $\mathrm{WM}$, both the yield point and tensile strength were equivalent to the base metal. For the HAZ, both the yield point and tensile strength were higher than the minimum specified strengths for SA440C (base metal) as shown in Table 1 (JISF 2004). However, the softening by welding heat input caused the yield point and tensile strength in the HAZ to be below the actual yield and tensile strengths of the base metal.

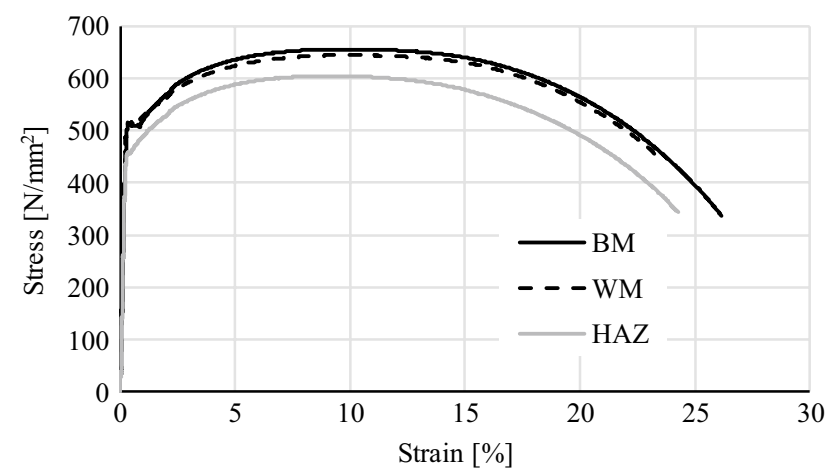

Fig. 6 Stress-strain relationships

\subsection{Charpy Impact Test}

\subsubsection{Specimen for the Charpy Impact Test}

Specimens for the Charpy impact test were the V-notch type, as shown in Fig. 7. According to JIS Z2242, the size of each specimen was $10 \mathrm{~mm} \times 10 \mathrm{~mm} \times 55 \mathrm{~mm}$. Specimens were cut from the BM and submerged arc weld regions. For the $\mathrm{BM}$, the specimen was cut out from the $1 / 4$ thickness location of the plate (Iyama et al. 2019). For the submerged arc weld region, specimens were fabricated from the bottom of the welded part, as shown by the hatched area in Fig. 8. The specimens named SA-WM, SA-D1, SA-B, and SA-H1 were prepared with different notch locations, as shown in Fig. 9. The notch of the SA-WM specimen was located center of the $\mathrm{WM}$, that of SA-D1 was located $1 \mathrm{~mm}$ toward the WM from the fusion (bond) line, that of SA-B specimen was located on the fusion line and that of SA-H1 was located $1 \mathrm{~mm}$ from the fusion line toward the BM.

\subsubsection{Testing Condition of the Charpy Impact Test}

In each series (BM, SA-WM, SA-D1, SA-B, SA-H1), five test temperatures $\left(-60{ }^{\circ} \mathrm{C},-40{ }^{\circ} \mathrm{C},-20^{\circ} \mathrm{C}, 0{ }^{\circ} \mathrm{C}, 20^{\circ} \mathrm{C}\right)$ were selected. For repeatability, three tests were performed at each series and temperature.
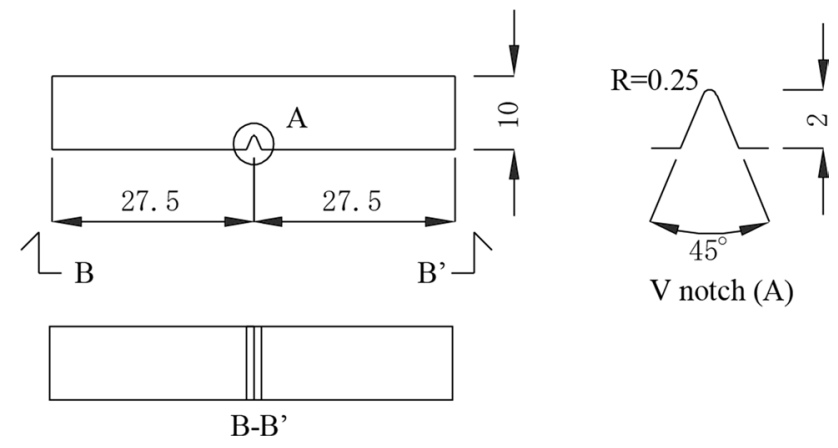

Fig. 7 Shape of the specimen for the Charpy impact test
Table 5 Results of the coupon test

\begin{tabular}{|c|c|c|c|c|c|c|}
\hline \multirow[t]{2}{*}{ Location } & \multirow[t]{2}{*}{ Temperature } & \multicolumn{2}{|c|}{ Yield Point $\left(\mathrm{N} / \mathrm{mm}^{2}\right)$} & \multirow{2}{*}{$\begin{array}{l}\text { Tensile strength } \\
\left(\mathrm{N} / \mathrm{mm}^{2}\right)\end{array}$} & \multicolumn{2}{|c|}{ Elongation (\%) } \\
\hline & & Upper & Lower & & Uniform & Fracture \\
\hline $\mathrm{BM}$ & $0{ }^{\circ} \mathrm{C}$ & 516 & 507 & 657 & 10.3 & 26 \\
\hline WM & $0{ }^{\circ} \mathrm{C}$ & 530 & 521 & 646 & 10.2 & 23 \\
\hline HAZ & $0{ }^{\circ} \mathrm{C}$ & $452 *$ & & 601 & 9.4 & 24 \\
\hline
\end{tabular}

$* 0.2 \%$ offset yield strength 


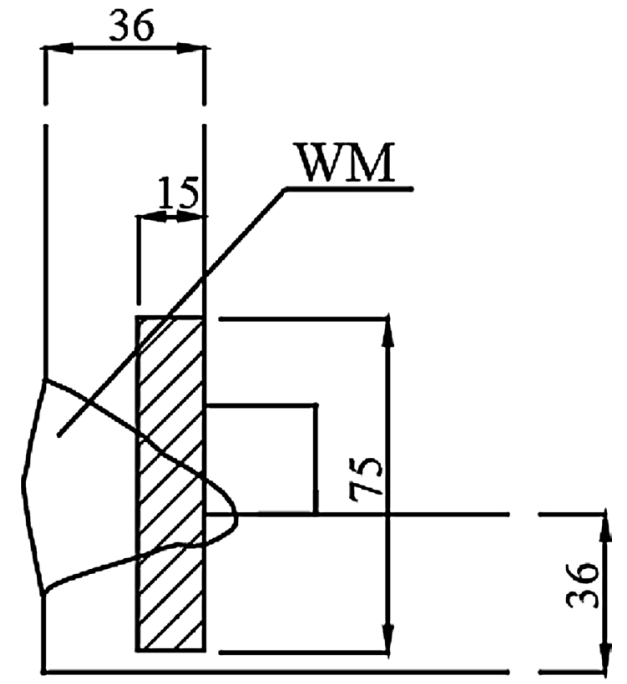

Fig. 8 Location of the submerged arc welded specimen for the Charpy impact test

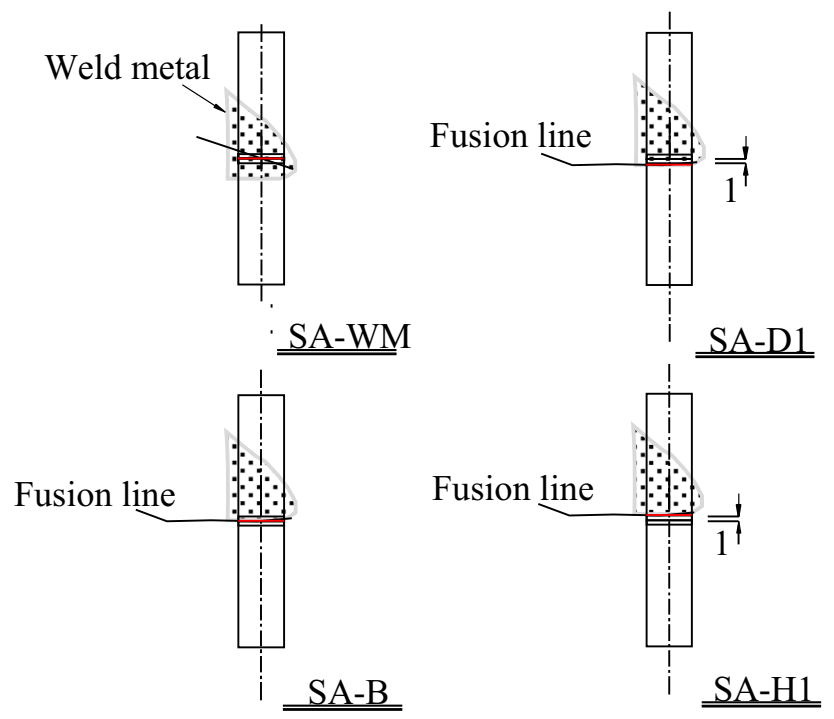

Fig. 9 Location of notch for the SA-WM, SA-D1, SA-B, and SA-H1 specimens

\subsubsection{Results of the Charpy Impact Test}

The Charpy impact test results from the BM samples are shown in Fig. 10, and the test results from the SA-WM, SA-D1, SA-B and SA-H1 samples are shown in Fig. 11. The Charpy absorbed energy ${ }_{v} E$ is shown in the left column, the percent cleavage fracture (in ISO 148-1; and the term is also referred to as the percent brittle fracture in JIS G0202) $B A$ is shown in the right column, and the test temperature is shown on the horizontal axis. In each graph, the filled circles denote ${ }_{v} E$, the open circles denote $B A$, and the dashed line and solid line denote the average of ${ }_{v} E$ and $B A$.

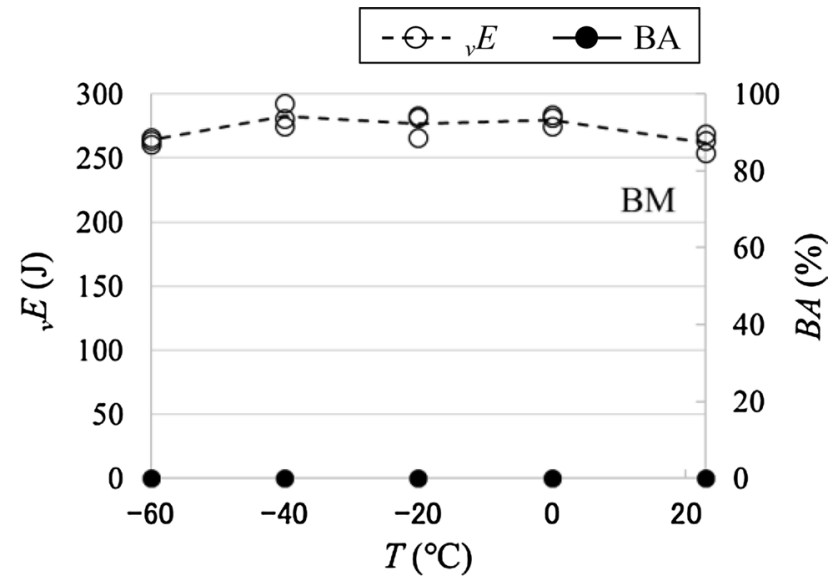

Fig. 10 Test results of BM samples

The BM exhibited an absorbed energy of ${ }_{v} E=280 \mathrm{~J}$ and a percent brittle fracture of $B A=0 \%$ at $0{ }^{\circ} \mathrm{C}$. Both the energy transition temperature and the fracture appearance transition temperature are less than $-60{ }^{\circ} \mathrm{C}$. These results indicate that it is a material with considerably high notch toughness. On the other hand, the absorbed energy and percent brittle fracture of the WM at $0{ }^{\circ} \mathrm{C}$ are ${ }_{v} E=58 \mathrm{~J}$ and $B A=52 \%$, respectively. The fracture appearance transition temperature of the WM is approximately $0{ }^{\circ} \mathrm{C}$. Furthermore, the absorbed energy and percent brittle fracture of the fusion line at $0{ }^{\circ} \mathrm{C}$ are ${ }_{v} E=29 \mathrm{~J}$ and $B A=90 \%$, respectively. The fracture appearance transition temperature of the fusion line is more than $20{ }^{\circ} \mathrm{C}$. Compared with the BM, the notch toughness of the fusion line is very low and caused by grain coarsening, which is caused by the large heat input of the SAW process.

\subsection{Vickers Hardness Test}

\subsubsection{Testing Method for the Vickers Hardness Test}

To investigate the mechanical properties around the submerged arc weld, a Vickers hardness test was conducted with a test load of $5 \mathrm{kgf}(49.03 \mathrm{~N})$. As shown in Fig. 12a, the Vickers hardness was measured along three lines with $x=2,16$, and $32 \mathrm{~mm}$. The pitch of the measured points was determined according to the distance from the fusion line, as shown in Fig. 12b.

\subsubsection{Test Results of the Vickers Hardness Test}

The distribution of the Vickers hardness data is shown in Fig. 13. In all the measured lines, the hardness of the HAZ is lower than those of the BM and WM. The low hardness was caused by a large heat input during the SAW process and a slow cooling rate. On the other hand, the hardness of the WM is almost the same as that of the BM. These results 


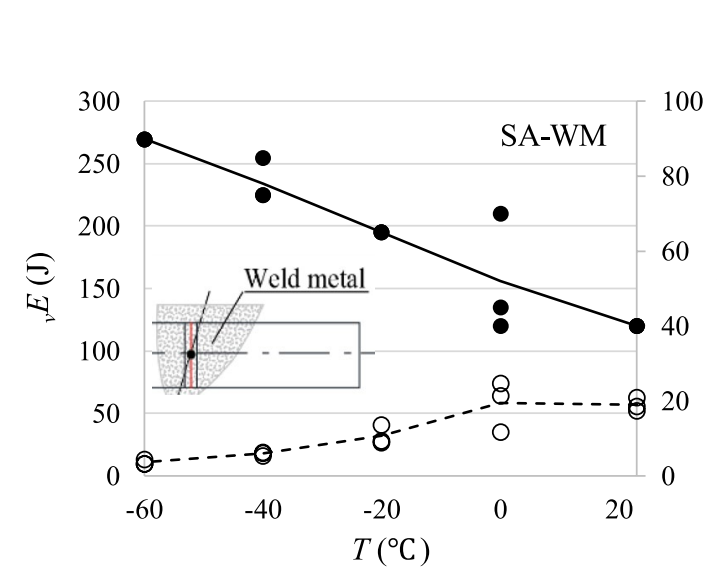

(1) weld metal

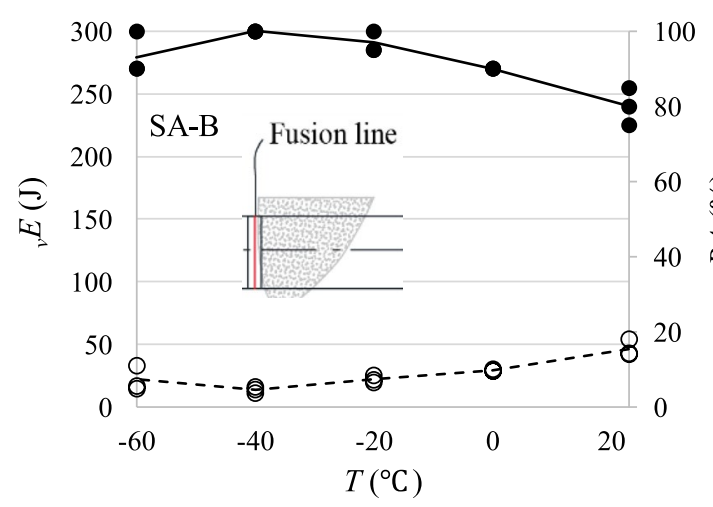

(3) Fusion line

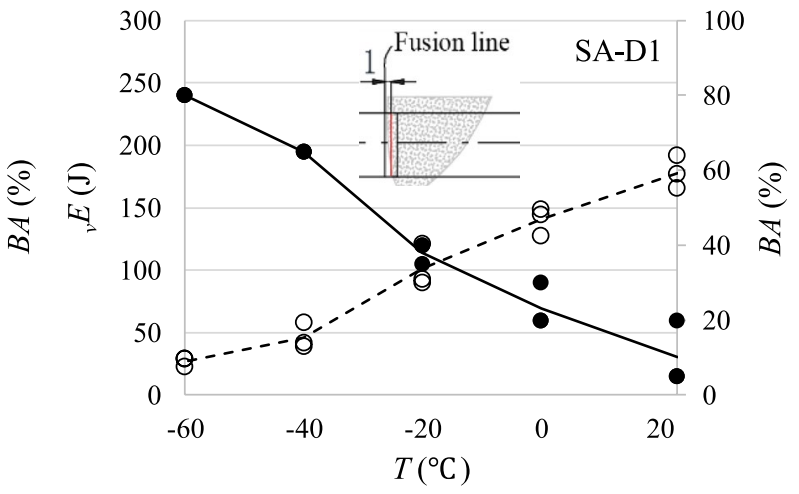

(2) HAZ $1 \mathrm{~mm}$ from fusion line

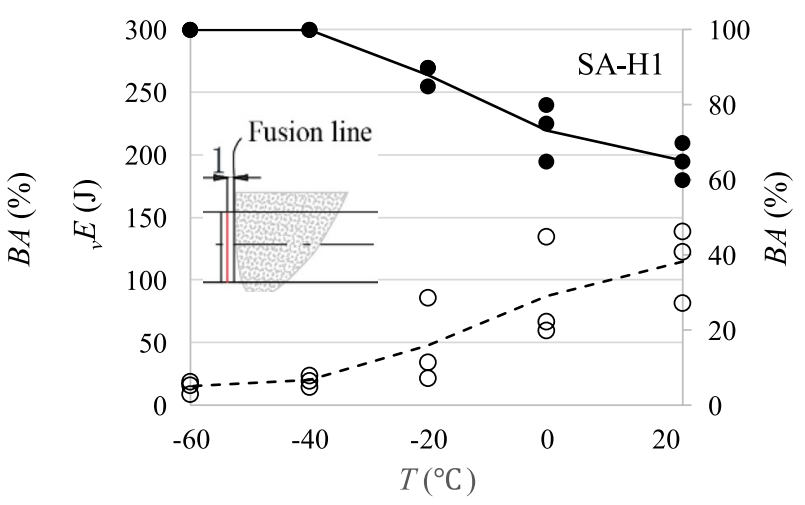

(4) Weld metal $1 \mathrm{~mm}$ from fusion line

Fig. 11 Test results of submerged arc welded samples

Fig. 12 Measurement positions. a The position of three lines, $\mathbf{b}$ The distribution of the measured pitch

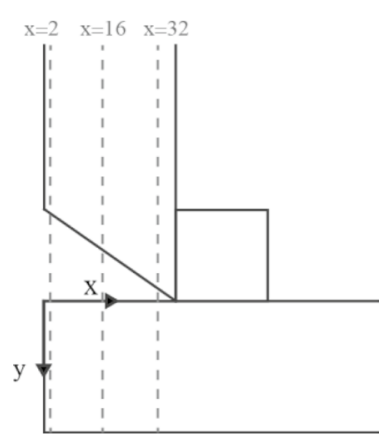

(a) The position of three lines

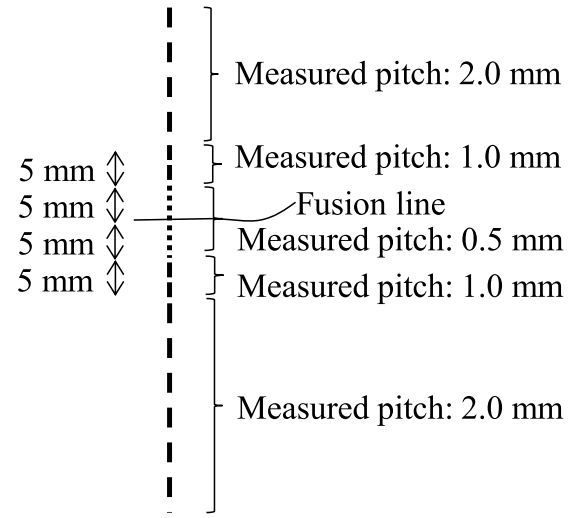

(b) The distribution of the measured pitch 

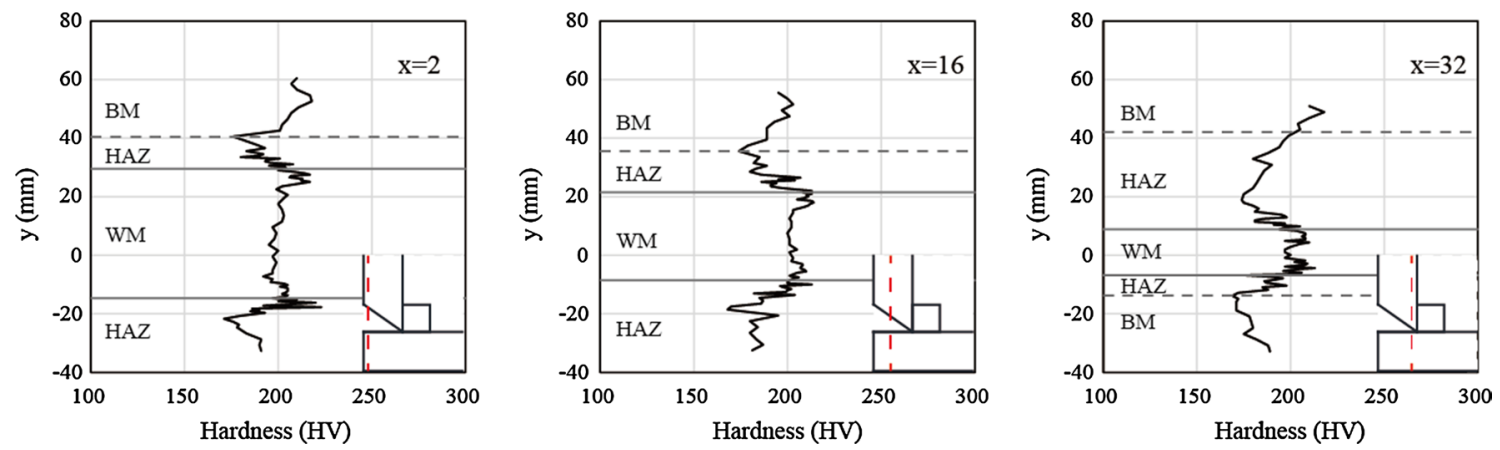

Fig. 13 Hardness distribution

correspond to the results of the coupon test described in Sect. 3.1.

\section{Bending Test of Corner Welding}

\subsection{Specimen for the Bending Test}

To investigate the toughness of SA440C corner weld fabricated by SAW, a bending test was conducted. Two L-shaped specimens $(\mathrm{S} 1, \mathrm{~S} 2)$ cut from the corner of a built-up box column with dimensions of $800 \times 800 \times 36$ (SA $440 \mathrm{C}$ ) were used, as shown in Fig. 14. The macroscopic cross-section photos in the vicinity of the position where both specimens were cut from are shown in Fig. 15. Due to ultrasonic testing (UT) performed prior to the bending test, a welding defect of incomplete penetration was found in Specimen 2 (S2). The length of the defect is larger than the allowable value in the Japanese standard for weld defects (AIJ 2008). The location of the defect is shown in Fig. 16.

\subsection{Setup and Loading Protocol}

The test apparatus is shown in Fig. 17. The bottom of the specimen is fixed to the reaction beam. The top of the specimen is connected to the actuator via the loading beam, and it is loaded in the horizontal direction. The actuator, the loading beam, and the specimen are connected with a
Fig. 14 Geometry of the specimen for the bending test
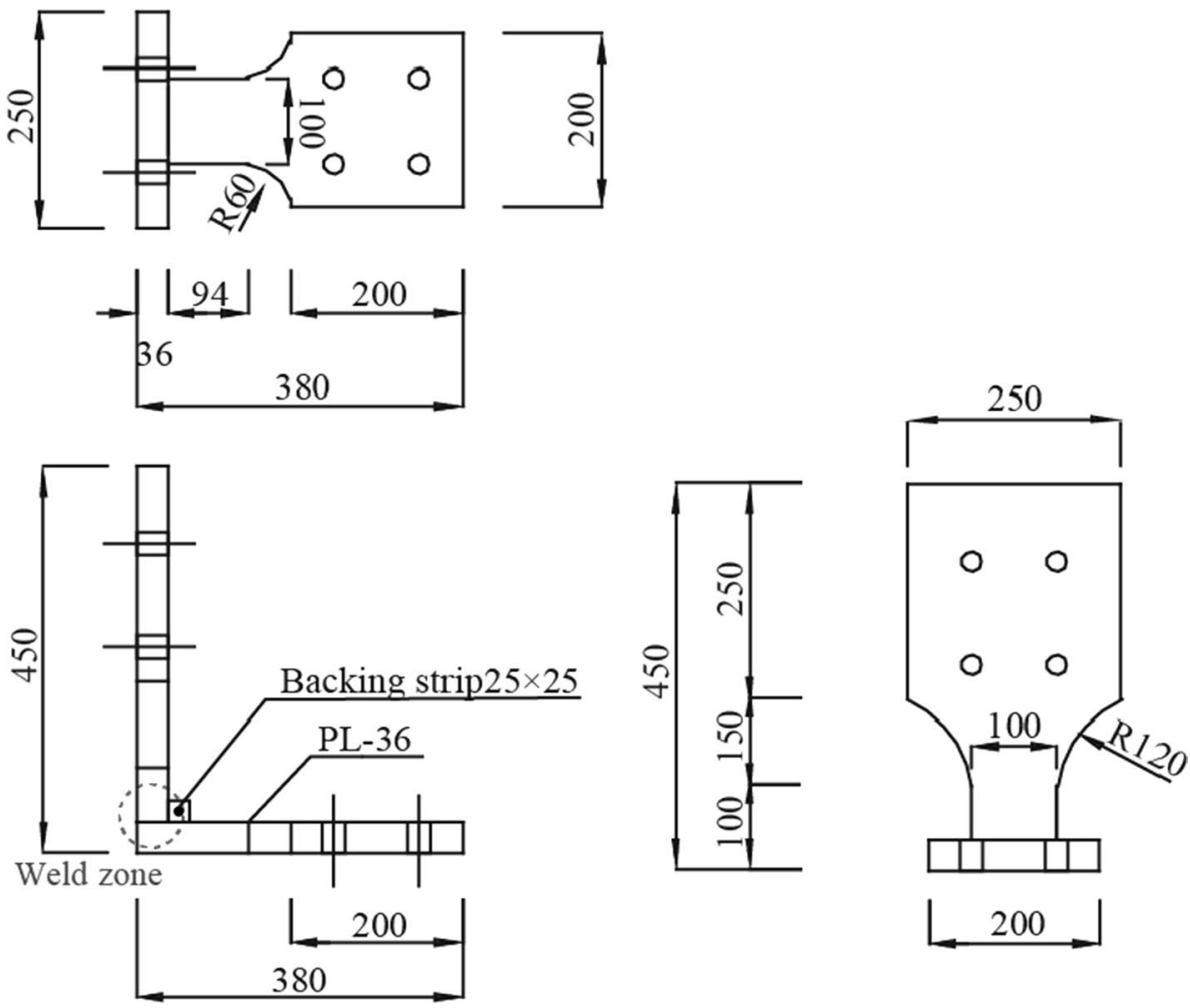
Fig. 15 Macroscopic cross-section photo (the vicinity of the cut position). (1) S1, (2) S2

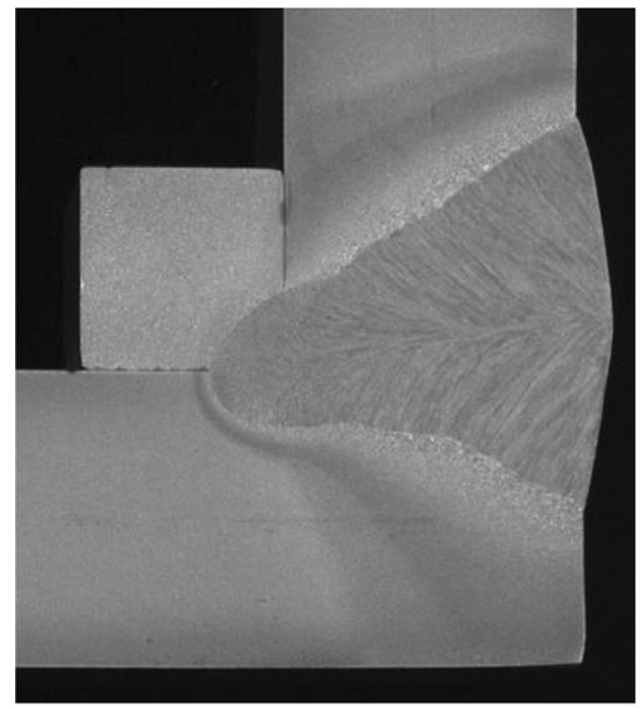

(1) S1

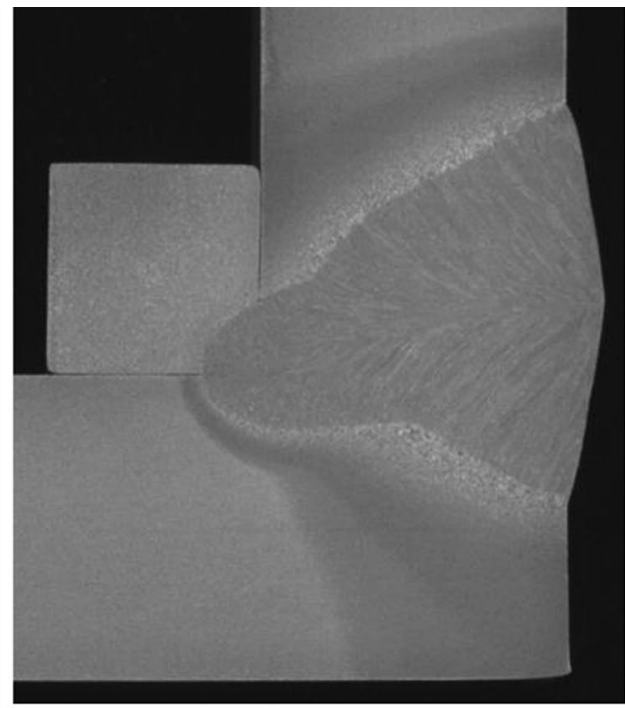

(2) S2

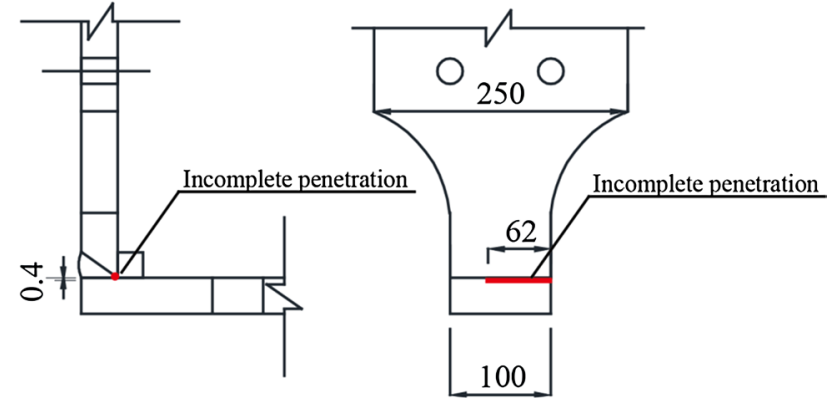

Fig. 16 Location of the defect of the weld of the S2 specimen

$14 \mathrm{~mm}$ thick plate at the location shown as "pin" in the flange. Although the "pin" is not a mechanical pin joint, the rotational stiffness is small enough to be considered a hinge. Simulating the out-of-plane deformation of the column flange under earthquake, cyclic loading was applied with an amplitude of 0-45 $\mathrm{mm}$ to the displacement of the tip of the actuator, $\delta_{\text {act}}$, as shown in Fig. 18.

To investigate whether the specimen would fracture in a brittle manner, or not, under low temperature, the specimen temperature was controlled during the first cycle. Before the first cycle, the specimen was cooled with dry ice. The first loading cycle was initiated when the temperature of the specimen, measured by two thermocouples placed in a small hole at both ends of the backing bar, was in the range of $0{ }^{\circ} \mathrm{C} \pm 3{ }^{\circ} \mathrm{C}$. It was confirmed that the temperature was in the proper range throughout the first loading cycle, but during the following cycles, the temperature was not controlled, as shown in Fig. 18. The cyclic loading continued until the peak load in a cycle decreased to $50 \%$ of the maximum load the specimen experienced.

\subsection{Test Results}

The load-deformation relations for both specimens are shown in Fig. 19. The first half-cycle of specimen S1 is shown in Fig. 20. The vertical axis represents the load $P$ applied by the actuator, and the horizontal axis represents the displacement $\delta_{\text {act }}$ of tip of the actuator. From Fig. 20, it is confirmed that the loading amplitude of $\delta_{\text {act }}=45 \mathrm{~mm}$ is 4 times larger than the yield deformation of the specimen.

For specimen S1 without a weld defect, no cracks were observed in the 1st cycle in which the test temperature was controlled in the range of $0 \pm 3{ }^{\circ} \mathrm{C}$. In the 2 nd and subsequent cycles, the peak load in each cycle slowly decreased. During the 35th cycle, sudden drops of the load occurred twice with an audible sound from the metal. Small cracks were observed in the slit between the backing strip and the flange plate. In the 51st cycle, the peak load decreased to $50 \%$ of that of the 1st cycle, and the test was terminated.

For specimen S2, as similar to specimen S1, no cracks were observed during the 1 st cycle in which the test temperature was controlled to $\pm 3{ }^{\circ} \mathrm{C}$. In the 2 nd and subsequent cycles, the peak load in each cycle slowly decreased. In the 21 st cycle, a sudden drop of the load was observed with an audible sound from the metal, but a small crack was observed in the slit between the backing strip and the flange plate after the 22th cycle. After the crack gradually appeared on the surface in the 49th cycle, the test was terminated because the peak load decreased to $50 \%$ of that of the 1 st cycle. 
Fig. 17 Apparatus
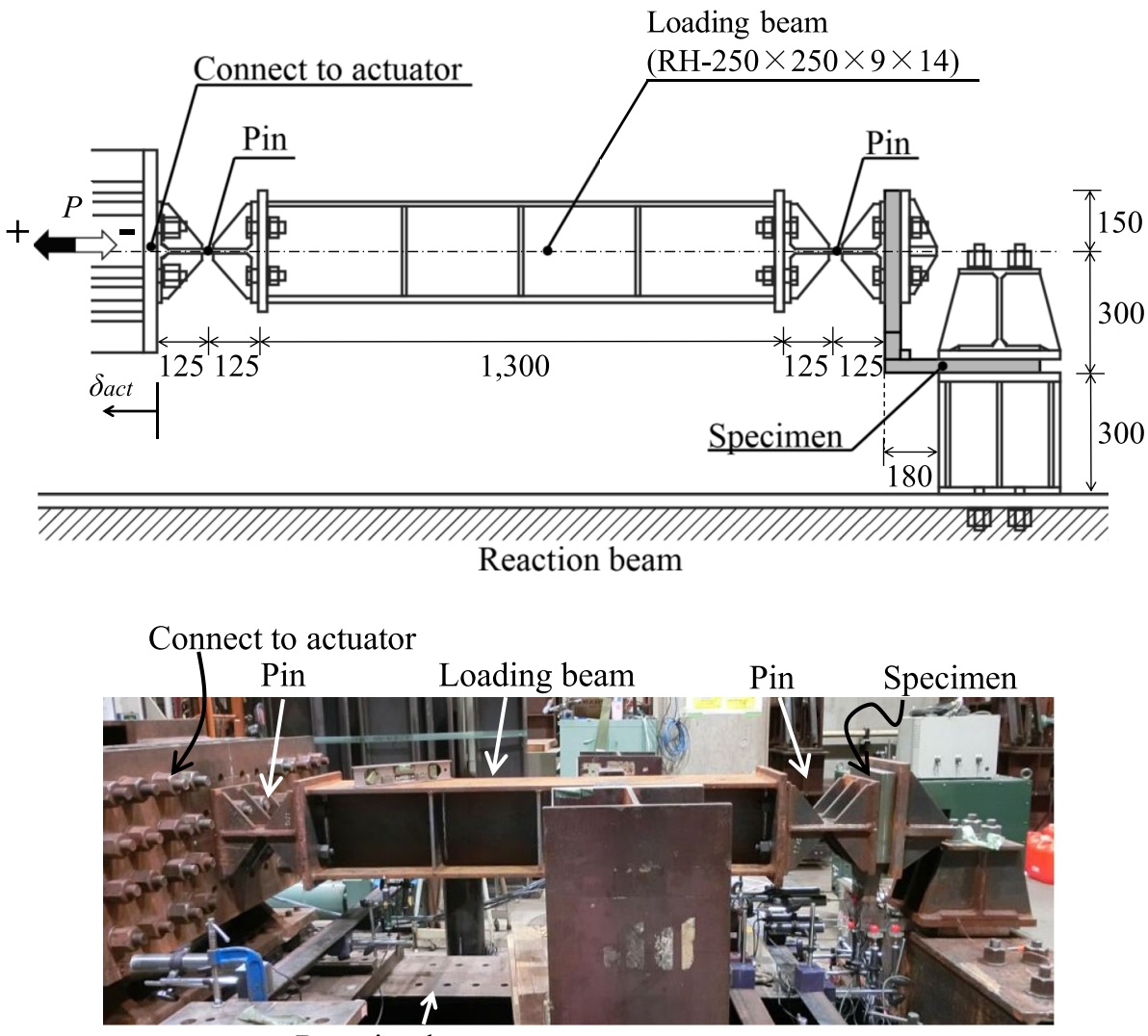

Reaction beam

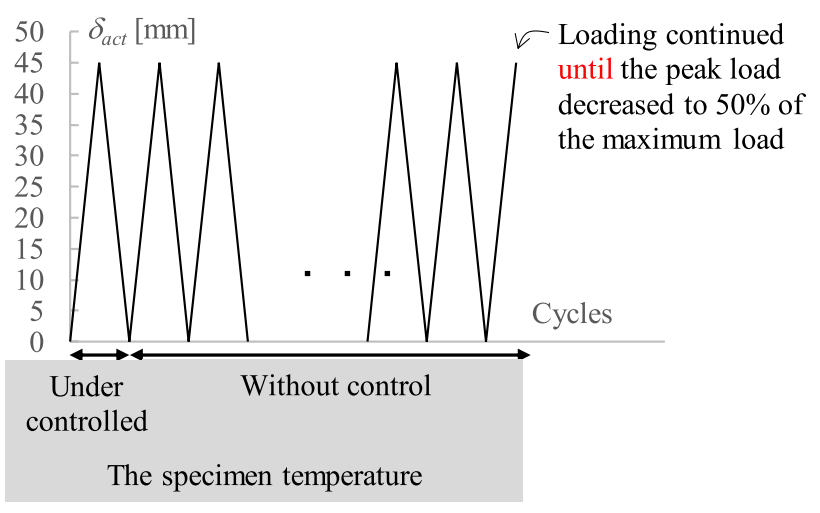

Fig. 18 Loading and temperature controlling protocol
The cracks on both specimens after the last cycle loading are shown in Fig. 21. The shapes of the cracks for both specimens are almost the same. The crack initiated at the slit tip between the backing strip and the flange plate and propagated in the direction or 45 degrees through the HAZ, whose strength was decreased by heat input of welding. The notch toughness of the fusion line was very low, ${ }_{v} E=29 \mathrm{~J}$, as shown in Fig. 10, but no crack or brittle fracture occurred along the fusion line, probably because the strength is higher than that of the HAZ, as shown in Fig. 13.

The change in the peak load of each cycle of both specimens is shown in Fig. 22. The slopes of the peak load for both specimens are similar until a sudden load drop was
Fig. 19 Load-deformation relationships
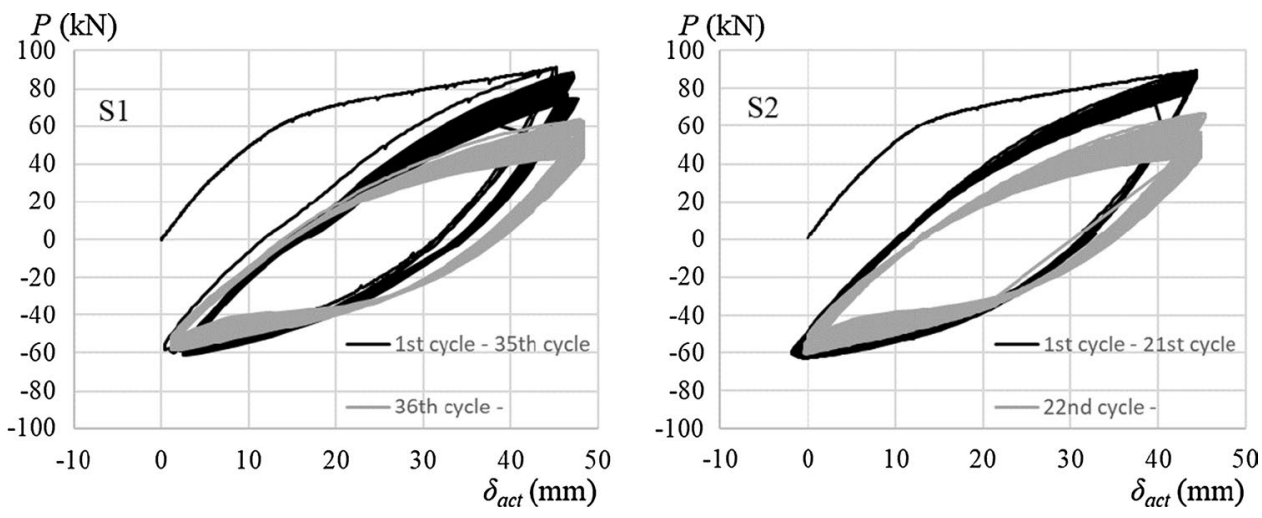


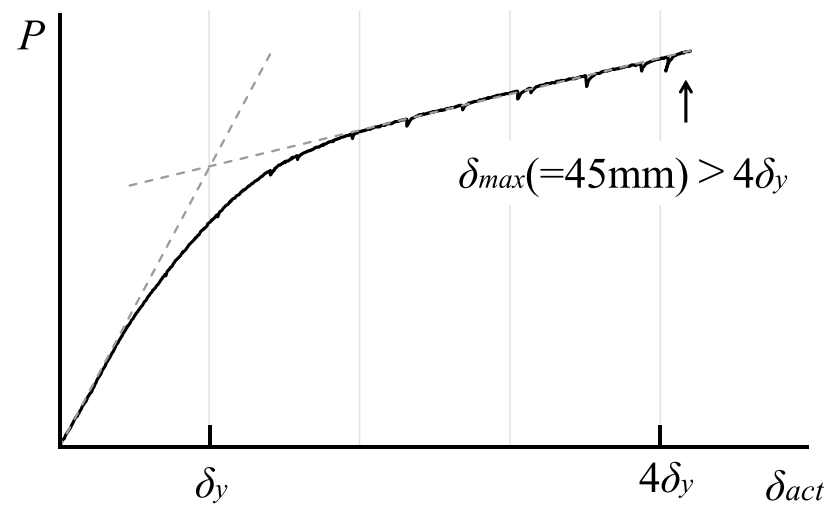

Fig. 20 First half cycle of specimen S1

observed due to crack initiation. The load drop occurred earlier in the S2 specimen than in the S1 specimen, likely because of the welding defect, but the fracture was not brittle in nature. The degradation of the strength after the crack initiation was slow because approximately 50 cycles were necessary until the peak load decreased to $50 \%$ of the maximum. From this result, it can be concluded that the ductility of the submerged arc welded joint at the corner of the builtup box column was sufficiently large against the tensile force from the beam flange, even though it had welding defects that are not acceptable according to the Japanese standards of welding defect (AIJ 2008).

\section{Conclusion}

To estimate the ductility of the welding corner joint of highperformance SA440C steel fabricated by SAW under standard welding conditions in Japan, a series of material and cyclic loading tests of the corner joint were conducted. The obtained results are summarized as follows.
From the coupon test and Vickers hardness test, it was observed that the strength of WM was equivalent to the BM. However, although the strength of the HAZ satisfied the specification, it became lower than BM and WM due to the high heat input. The strength of the fusion line became higher than that of the BM and WM.

From the Charpy impact test, it was observed that, although the notch toughness of the BM was very high, those of the WM and HAZ were not high. Especially at the fusion line, the notch toughness was poor.

During the cyclic loading test of the corner joint, two specimens were examined, including a specimen without a weld defect and a specimen with incomplete penetration. In both specimens, even though the strength decreased with the generation and propagation of cracks, brittle fracture did not occur. From this result, it was confirmed that the submerged arc welded corner joint of high-performance SA440 steel has sufficient ductility.

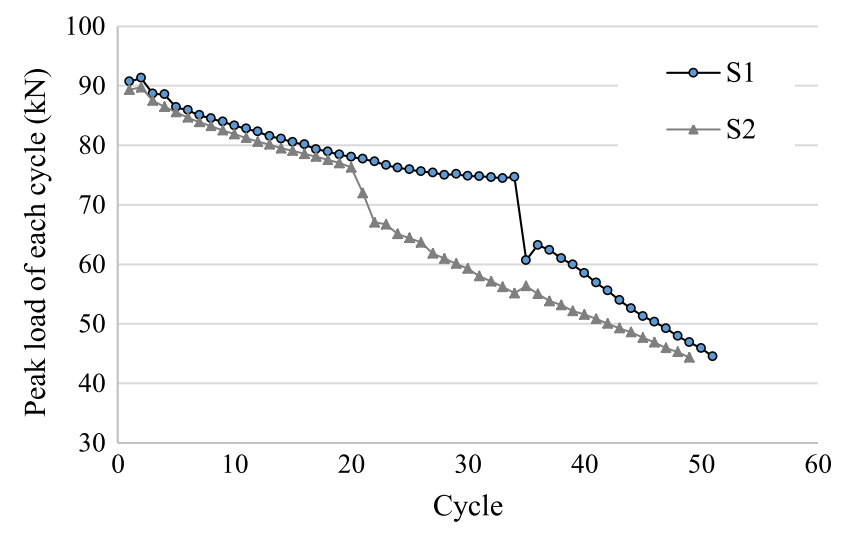

Fig. 22 Transition of peak load of each cycle
Fig. 21 The cracks after the last loading cycle. (1) S1, (2) S2

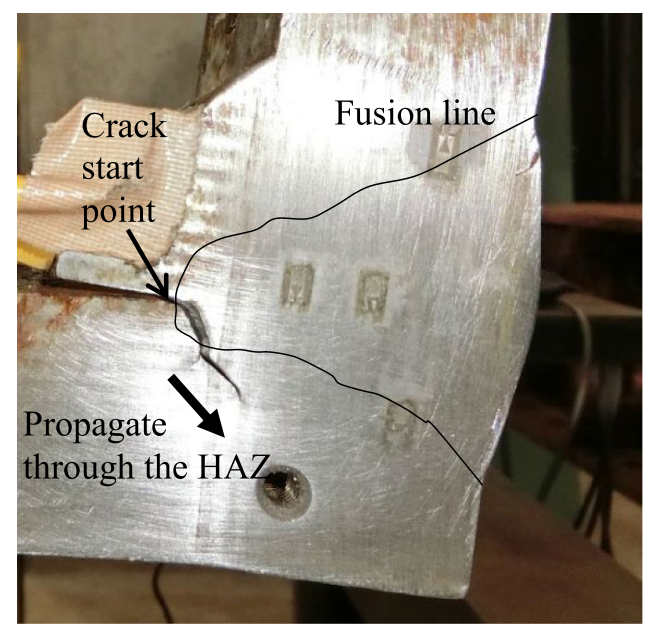

(1) S1

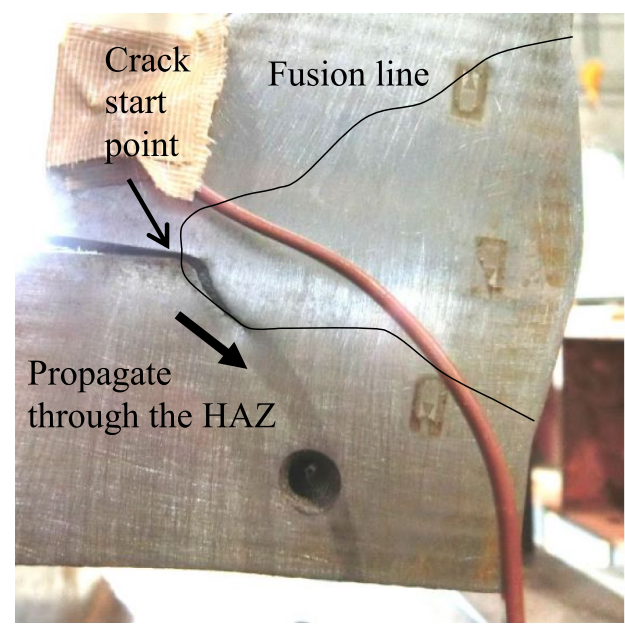

(2) $\mathrm{S} 2$ 
Acknowledgements This research is conducted by the "Research Committee on Required Performance of Welding" (Head: Prof. Satoshi Yamada from Tokyo Institute of Technology), Japanese Society of Steel Construction (JSSC) and was financially supported by the Research and Education Support Program of Japan Iron and Steel Federation (JISF). The authors are grateful to JSSC and JISF as well as other members of the committee.

Open Access This article is licensed under a Creative Commons Attribution 4.0 International License, which permits use, sharing, adaptation, distribution and reproduction in any medium or format, as long as you give appropriate credit to the original author(s) and the source, provide a link to the Creative Commons licence, and indicate if changes were made. The images or other third party material in this article are included in the article's Creative Commons licence, unless indicated otherwise in a credit line to the material. If material is not included in the article's Creative Commons licence and your intended use is not permitted by statutory regulation or exceeds the permitted use, you will need to obtain permission directly from the copyright holder. To view a copy of this licence, visit http://creativecommons.org/licenses/by/4.0/.

\section{References}

AIJ (Architectural Institute of Japan). (2008). Standard for ultrasonic inspection of weld defects in steel structures, 5th Ed. (in Japanese).

ISO (International Organization for Standardization) 148-1:2006. (2006). Metallic materials - Charpy pendulum impact test — Part 1: Test method.

Iyama, J., Matsumoto, Y., Ishii, T., Shimokawa, H., Nikaido, M., \& Yamada, S. (2019). Fracture strength of an electroslag welding joint with high-performance steel. Journal of Constructional Steel Research, 153, 495-508.

JIS (Japanese Industrial Standards) G0202:2013. (2013). Glossary of terms used in iron and steel.

JIS (Japanese Industrial Standards) Z 2242:2018. (2018). Method for Charpy pendulum impact test of metallic materials.

JIS (Japanese Industrial Standards) Z 3111:2005. (2005). Methods of tension and impact tests for deposited metal.

JIS (Japanese Industrial Standards) Z 3351:2012. (2012). Solid wires for submerged arc welding of carbon steel and low alloy steel.

JIS (Japanese Industrial Standards) Z 3352:2017. (2017). Fluxes for submerged arc welding and electroslag welding.

JISF (the Japan Iron and Steel Federation). (2004). High performance $590 \mathrm{~N} / \mathrm{mm}^{2}$ steel for building structures (SA440), JISF Specification No. MDCR 0013-2004 (in Japanese).

JISF (the Japan Iron and Steel Federation). (2016). Design and welding process guideline for high performance $590 \mathrm{~N} / \mathrm{mm}^{2}$ steel (SA440), 3rd Ed. (in Japanese).

Kojima, A., Yoshii, K., Hada, T., Saeki, O., Ichikawa, K., Yoshida, Y., Shimura, Y., \& Azuma, K. (2004). Development of high HAZ toughness steel plates for box columns with high heat input welding. Nippon Steel Technical Report, No. 90, pp. 39-44.

Wada, T., Terasaki, T., \& Igi, S. (1998). Prevention of HAZ cracking in corner joints of high heat input SAW box columns. Welding International, 12(3), 207-214.

Yoshida, T., Onoe, H., Kumabe, H., \& Tsukui, H. (1963). Study on submerged arc welding for HT-80 steel. Journal of the Japan Welding Society, 32(12), 1134-1142. (in Japanese).

Publisher's Note Springer Nature remains neutral with regard to jurisdictional claims in published maps and institutional affiliations. 